\title{
Development of quality indicators based on a multidisciplinary, evidence-based guideline on pediatric constipation
}

\author{
Jozette J. C. Stienen • Merit M. Tabbers • \\ Marc A. Benninga $\cdot$ Mirjam Harmsen • \\ Mariëlle M. T. J. Ouwens
}

Received: 17 January 2011 / Accepted: 21 March 2011 /Published online: 13 April 2011

(C) The Author(s) 2011. This article is published with open access at Springerlink.com

\begin{abstract}
Several clinical guidelines for childhood functional constipation have been developed, but none of them is accompanied by a set of quality indicators. It is important to gain insight into the quality of care in daily practice in order to improve the implementation of clinical guidelines. This can be done by developing and measuring quality indicators. We identified a set of quality indicators for diagnosis and treatment of children with functional constipation, based on the existing Dutch evidence-based multidisciplinary guideline 'Functional constipation in children between 0 and 18 years' and expert opinions of professionals and patients. Assessment of the initial 84 potential quality indicators was done by using a RANDmodified Delphi method. The final set consisted of seven representative quality indicators (one structure and six process quality indicators) for children with functional constipation, covering the dimensions of diagnosis, medical treatment, non-medical treatment and referral. This study describes a systematic method to develop a set of seven process and structure quality indicators that can be used to monitor quality of health care for children with functional constipation.
\end{abstract}

Electronic supplementary material The online version of this article (doi:10.1007/s00431-011-1458-x) contains supplementary material, which is available to authorized users.

J. J. C. Stienen $(\bowtie) \cdot$ M. Harmsen $\cdot$ M. M. T. J. Ouwens

Scientific Institute for Quality of Healthcare,

Radboud University Nijmegen Medical Centre,

Nijmegen, The Netherlands

e-mail: J.Stienen@iq.umcn.nl

M. M. Tabbers $\cdot$ M. A. Benninga

Department of Pediatric Gastroenterology and Nutrition,

Emma Children's Hospital/Academic Medical Centre Amsterdam,

Amsterdam, The Netherlands
Keywords Quality indicators · Functional constipation . Pediatric guideline Implementation · Quality of health care $\cdot$ Consensus

\section{Introduction}

The pathophysiology of childhood constipation consists of multiple factors. Because in the vast majority of patients no evidence can be found of an inflammatory, anatomic, metabolic or neoplastic process that explains the subject's symptoms, these patients are considered to have a functional disorder [5]. Functional constipation is a worldwide digestive problem in children and adults $[28,36]$. Studies in the USA and the Netherlands showed that $10-45 \%$ of the children visiting pediatric gastroenterologists have constipation-related complaints [1, 7, 22, 35].

Functional constipation often is multifactorial and can have potential invalidating consequences such as frequent absence from school, social desolation and feelings of depression [5]. However, evidence on the optimal care for patients with functional constipation is scarce. Therefore, a multidisciplinary group of professionals in the Netherlands took the initiative to develop a national guideline on the diagnosis, treatment and follow-up of children with functional constipation.

To improve care, insight into actual care and adherence to the guideline is necessary. Actual care can be measured with quality indicators, which can indirectly lead to insight into the process of quality improvement in care [8, 12]. Quality indicators are 'measurable elements of practice performance for which there is evidence or consensus that they can be used to assess the quality of care' [2], and they are often translated out of recommendations from relevant clinical guidelines and literature. Quality indicators aim to detect the quality of care either in the structure or the 
Fig. 1 Process of quality indicator selection
Multidisciplinary evidence-based guideline 'Functional constipation in children between 0 and 18 years

Step 1. Extraction of 84 recommendations from the guideline and classification into three dimensions: diagnosis, medical treatment and non-medical treatment

Step 2. Written appraisal of the 84 recommendations by the expert panel on relevance and selection of the three best recommendations by dimension and overall

Step 3. Processing the results with the consensus-tool:

3 recommendations 'selected' 24 recommendations 'equivocal' 57 recommendations 'non-selected'

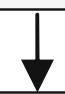

Step 4. Consensus meeting of the expert panel ending in selection of the 11 best recommendations

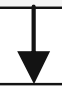

Step 5. Translation of the recommendations into indicators and final comments of the expert panel:

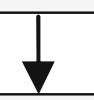

Step 6. Practice test to assess the measurability of the indicators

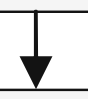

A final set of 7 quality indicators 
process of medical care or in the outcome of delivered care [21]. Structure indicators assess health system characteristics such as number of staff and supplies, whereas process indicators refer to what professionals did for the patient and how well it was done. The outcome indicators assess outcomes of delivered care, which ideally can be expressed in the five Ds (dead, disease, discomfort, disability and dissatisfaction) [19]. To our knowledge, no quality indicators have yet been developed for children with functional constipation.

This paper reports on the development of quality indicators for care delivered to children with functional constipation, based on the Dutch evidence-based multidisciplinary guideline 'Functional constipation in children between 0 and 18 years' [5]. These indicators can be helpful in improving care for children with functional constipation. Actual care can be assessed, and low scores of the indicators point out that improvement activities are needed.

\section{Methods and Results}

The basis for the development of the quality indicators was the multidisciplinary evidence-based guideline 'Functional constipation in children between 0 and 18 years'. The RAND-modified-Delphi method, a procedure that combines evidence from the guideline with expert opinions, was used to reach consensus $[3,4,30]$. The steps taken have been visualized in Fig. 1 and described below.

\section{Step 1. Extraction and classification of recommendations} from the guideline

Two researchers (MH and JS) extracted all 84 recommendations from the guideline and classified these recommendations into four dimensions: diagnosis $(N=23)$, medical treatment $(N=22)$, non-medical treatment $(N=15)$ and referral $(N=24)$.

Step 2. Written appraisal of recommendations by the expert panel

A representative panel of 21 experts (e.g. general practitioners, pediatric gastroenterologists (including co-authors MB and MT), primary health care doctors, pediatricians, clinical epidemiologists, a pediatric physiotherapist, a pediatric surgeon, a psychologist, the chair of the patient association, a hospital pharmacist and a nurse consultant, who had been involved in the guideline development, was also approached to participate in the development of the quality indicators. The panel was asked to score the recommendations on the relevance to the quality of care for children with functional constipation. A nine-point
Likert scale ranging from 1 (hardly relevant) to 9 (extremely relevant) was used to rate the recommendations. A category 'could not assess' was also available. Besides, the panel was asked to give their top ranking: the best recommendation by dimension (diagnosis, medical treatment, non-medical treatment and referral) and the three overall most relevant recommendations for the quality of care (top-three ranking). Remarks about the recommendations were also allowed.

\section{Step 3. Processing the results}

Subsequently, the results were analyzed using a standardized consensus tool, and the recommendations were rated as valid if they matched three of our criteria. The first two criteria include that the recommendation was rated with a median score of eight or nine and that there was agreement among the ratings of the independent panel members. Agreement was defined as the case in which $70 \%$ or more of the scores was in the top tertile (scores 7, 8 or 9) of the scale and the other $30 \%$ or less of the scores was divided over the remaining two tertiles. These criteria were deduced from the two of Campbell's criteria [3].

Earlier research on indicator development showed that using only the criteria mentioned above, often does not provide enough discrimination [3, 4]. Therefore, a third criterion was added: the recommendation should be in the top ranking for $20 \%$ of the scores [16, 23]. Points were awarded according to the panels' best recommendation by dimension and the top-three ranking. A recommendation that was first mentioned in the top three was given four points, the second one was given three points and the third one two points. Recommendations that were selected as best recommendation in one of the four dimensions (without being mentioned in the top three) were given one point. These points were converted into percentages based on the number of experts that scored that recommendation and the related maximum score.

An access-based consensus tool combined the three criteria as described above and converted them into three categories: 'selected', 'equivocal' or 'non-selected'. In this way, recommendations that met all three criteria were classified as 'selected', those who met at least one and a half criteria as 'equivocal' and the remaining recommendations as 'non-selected' (Table 1). The consensus tool listings were the input for the next round, a consensus meeting.

Step 4. Consensus meeting of the expert panel

All members of the expert panel were invited to the consensus meeting to discuss the results of step 3. All recommendations were discussed with special attention to the 'equivocal' ones. Apart from the relevance to the quality of care for children 
Table 1 Example of consensus tool methodology to select recommendations and quality indicators, based on a selection of recommendations

\begin{tabular}{|c|c|c|c|c|c|c|c|c|c|c|c|c|c|c|c|c|}
\hline Example of recommendation & $\mathbf{N}$ & 1 & 2 & $\begin{array}{l}Q \\
3\end{array}$ & 4 & $\begin{array}{c}y \\
5\end{array}$ & $\begin{array}{l}\text { eas } \\
6\end{array}$ & ure & 8 & 9 & $\begin{array}{c}\text { 1st } \\
\text { tertile } \\
(1-3)\end{array}$ & $\begin{array}{c}\text { 2nd } \\
\text { tertile } \\
(4-6)\end{array}$ & $\begin{array}{c}\text { 3rd } \\
\text { tertile } \\
(7-9)\end{array}$ & $\begin{array}{c}\text { Top } 4 \\
\text { percentage }\end{array}$ & Median & $\begin{array}{l}\text { Guide for } \\
\text { conclusion }\end{array}$ \\
\hline $\begin{array}{l}\text { Professionals only diagnose children with } \\
\text { constipation when they fulfill two or more of the } \\
\text { ROME III criteria }\end{array}$ & 15 & 0 & 0 & 1 & 0 & 1 & 1 & 3 & 5 & 4 & $7 \%$ & $13 \%$ & $80 \%$ & $45 \%$ & 8 & Selected \\
\hline $\begin{array}{l}\text { Professionals do not make an additional abdominal } \\
\text { X-ray to diagnose children suspected of constipation }\end{array}$ & 14 & 0 & 0 & 0 & 0 & 4 & 0 & 4 & 2 & 4 & $0 \%$ & $29 \%$ & $71 \%$ & $17 \%$ & 7 & Equivocal \\
\hline $\begin{array}{l}\text { Professionals prescribe as initial treatment } 1 \text { - } \\
1.5 \mathrm{gram} / \mathrm{kg} / \text { day polyethylene glycol (PEG) to children } \\
\text { with fecal impaction }\end{array}$ & 12 & 0 & 0 & 1 & 0 & 1 & 0 & 3 & 4 & 3 & $8 \%$ & $8 \%$ & $83 \%$ & $0 \%$ & 8 & Equivocal \\
\hline $\begin{array}{l}\text { Professionals provide patients (and their parents) } \\
\text { with the course of constipation and the chance of } \\
\text { disappearance of the complaints }\end{array}$ & 15 & 0 & 0 & 0 & 0 & 1 & 1 & 1 & 7 & 5 & $0 \%$ & $13 \%$ & $87 \%$ & $10 \%$ & 8 & Equivocal \\
\hline $\begin{array}{l}\text { Professionals only use a rectal toucher as } \\
\text { supplementary diagnostic tool when the patient fulfills } \\
\text { only one of the ROME III criteria }\end{array}$ & 15 & 1 & 0 & 0 & 1 & 2 & 6 & 2 & 2 & 1 & $7 \%$ & $60 \%$ & $33 \%$ & $0 \%$ & 6 & $\begin{array}{l}\text { Non- } \\
\text { selected }\end{array}$ \\
\hline $\begin{array}{l}\text { Professionals never prescribe Colex when patients } \\
\text { are suspected of Hirschprung disease. }\end{array}$ & 11 & 0 & 1 & 0 & 0 & 3 & 1 & 0 & 1 & 5 & $9 \%$ & $36 \%$ & $55 \%$ & $0 \%$ & 8 & $\begin{array}{l}\text { Non- } \\
\text { selected }\end{array}$ \\
\hline
\end{tabular}

Ranking of the criteria: green $=$ valid, yellow $=$ equivocal, red = invalid. Based on these three criteria the consensus tool gives a guidance to draw conclusions during the consensus meeting about the relevance of the recommendations

with functional constipation, the recommendations were also assessed on their measurability and their 'room for improvement'. This consensus meeting, chaired by two of the authors (MO and JS), resulted in a set of consensus-based recommendations that best reflects the quality of care for children with functional constipation according to the expert panel.

Step 5.Translation of the recommendations into indicators and final comments of the expert panel

The chosen recommendations were translated into quality indicators, which means they were described as numerators and denominators (in the case of process and outcome indicators) or questions that could be answered with 'yes' or 'no' (in the case of structure indicators). The numerator represents the proportion of the patient population that applied the criteria as stated in the indicator. The term denominator represents the patient population to which the criteria (as stated in the indicator) should be applied. The quality indicators were e-mailed to all members of the expert panel for final comments and approval.

Step 6. Practice test to assess the measurability of the indicators

The indicators were tested on their measurability. Four professionals participated in the practice test: a general practitioner, a pediatric gastroenterologist and two primary health care doctors. All four professionals were asked to assess the measurability of the set of indicators based on data from ten randomly selected children with functional constipation. If data needed for an indicator could be collected by searching medical records or a patient survey, this was referred to as 'measurable'. The results of the practice test were evaluated with the four professionals individually by means of a semi-structured interview. Based on these results, the definitive set of quality indicators was determined.

\section{Results}

The 84 recommendations extracted from the guideline 'Functional constipation in children between 0 and 18 years' were scored by 16 of the 21 experts involved in the development of the guideline (five experts did not return the questionnaire). Twenty-seven of the recommendations met at least one criterion as described in step 3: 24 were classified as 'equivocal' and three were classified as 'selected' (Results are shown in the online appendix).

Eleven of the 21 experts were present at the consensus meeting. In advance, all experts were given the opportunity to comment on the results per e-mail. All 84 recommendations were discussed during the consensus meeting according to the consensus tool results. Eleven recommendations were selected for inclusion in the core set of the recommendations: one on diagnosis, eight on medical treatment, two on non-medical treatment and none on referral. Due to the overlap between some of the recommendations, these were combined into a definitive set of seven quality indicators (Table 2). The set includes one structure indicator on patient information and six process indicators. These process indicators dealt with the topics 'concerning diagnosis based on the ROME III criteria', 'medical treatment of polyethylene glycol and lactulose' and 'patient contact during and after medical treatment'.

All indicators were tested in the practice test and evaluated by four professionals. All indicators were found to be measurable, although there were some barriers. The Rome III criteria (indicator 1) were not explicitly used in a checklist, but were mostly written down in the medical record during a 
patient's visit with complaints. Therefore, data collection was found to be time-consuming. Another issue was the lack of information on the whole set of Rome III criteria. Besides, patient information as described in indicator 2 is mostly not kept at the professional's office, but available via other resources, such as the internet or patient organizations. These other resources are often not used by patients through lack of awareness. Unfortunately, it was not possible to measure whether professionals provided their patients with this information. In contrast, the indicators concerning medication use (indicators 3, 4 and 5) were well-registered and could be easily found in the medical records. However, general practitioners did not always register the duration of the medication but only the dosage, which made it more timeconsuming to collect the data. Contact with the patient 1 to 2 weeks after starting treatment (indicator 6) and 2 months after stopping treatment (indicator 7) was not yet a routine for most professionals, but these indicators were considered measurable if consultation dates had been documented.

None of the quality indicators were excluded after the practice test. The final set of quality indicators for care delivered to children with functional constipation consisted of seven quality indicators (Table 2).

\section{Discussion}

In this study, the quality indicators have been developed based on the recommendations of the Dutch evidence-based multidisciplinary guideline, 'Functional constipation in children between 0 and 18 years'. Assessing the quality of care using these quality indicators is essential for improving the quality of health care in children with functional constipation.

Clinical indicators must be developed and tested with scientific rigor in a transparent process. Although some good examples exist of sets of indicators that have been developed for the diagnosis, treatment and follow-up of patients with a specific disease or type of care $[15,16,23$, 27], these do not exist for children with functional constipation. Frequently used methods to assess the value of potential quality indicators are the Delphi technique and RAND appropriateness method [2]. In our study, we used the RAND-modified Delphi technique, with a nine-point Likert scale. Previous research showed that the method of rating recommendations on a Likert scale is reliable for the selection of indicators [18, 33]. The reliability of a consensus procedure is only moderate [34], but the reproducibility can be improved by choosing a high cut-off value and a top ranking. In the present study, the cut-off value of the potential quality indicators was a median score of eight or higher on a nine-point scale and the recommendation should be in the top ranking for $>20 \%$ of the scores $[16,23]$.

A multidisciplinary team of experts is required for the selection of quality indicators, to make sure that all aspects of the quality of care are discussed. All disciplines involved in health care for children with constipation were represented by one or more professionals in our expert team. Five experts did not fill out the questionnaire and ten did

Table 2 Selected quality indicators concerning quality of care for functional constipation in children

\begin{tabular}{|c|c|c|c|}
\hline & Quality indicator & $\begin{array}{l}\text { Type of } \\
\text { indicator }\end{array}$ & Dimension \\
\hline 1. & $\begin{array}{l}\text { Percentage of patients that are diagnosed with constipation, based on } \\
\text { two or more of the ROME III criteria }\end{array}$ & Process & Diagnosis \\
\hline 2. & $\begin{array}{l}\text { Availability of a brochure on pediatric constipation in the consulting- } \\
\text { room, including information about: } \\
\text { - The chronic character of constipation (course and chance of } \\
\text { disappearance) } \\
\text { - Toilet training }\end{array}$ & Structure & $\begin{array}{l}\text { Diagnosis and } \\
\text { non-medical } \\
\text { treatment }\end{array}$ \\
\hline 3. & $\begin{array}{l}\text { Percentage of patients (children aged } 1 \text { year or older) with constipation } \\
\text { that received polyethylene glycol (PEG) or lactulose as initial or } \\
\text { maintenance treatment }\end{array}$ & Process & $\begin{array}{l}\text { Medical } \\
\text { treatment }\end{array}$ \\
\hline 4. & $\begin{array}{l}\text { Percentage of patients (children younger than } 1 \text { year) with constipation } \\
\text { that received lactulose as initial or maintenance treatment } \\
\text { treatment }\end{array}$ & Process & $\begin{array}{l}\text { Medical } \\
\text { treatment }\end{array}$ \\
\hline 5. & Percentage of patients that received laxatives for at least 2 months & Process & $\begin{array}{l}\text { Medical } \\
\text { treatment }\end{array}$ \\
\hline 6. & $\begin{array}{l}\text { Percentage of patients whose professional contacted them and/or their } \\
\text { parents } 1 \text { to } 2 \text { weeks after starting treatment, depending on the severity } \\
\text { of constipation }\end{array}$ & Process & $\begin{array}{l}\text { Medical } \\
\text { treatment }\end{array}$ \\
\hline 7. & $\begin{array}{l}\text { Percentage of patients whose professional contacted them and/or their } \\
\text { parents } 2 \text { months after ending treatment to evaluate constipation }\end{array}$ & Process & $\begin{array}{l}\text { Medical } \\
\text { treatment }\end{array}$ \\
\hline
\end{tabular}


not attend the consensus meeting. This is not likely to disturb our results, because all experts were given the opportunity to comment on the results before and after the consensus meeting (which was done by a few experts). Furthermore, all specialisms were represented among the 16 experts that returned the questionnaire, and we believe that a response rate of $76 \%(16 / 21)$ for filling out a questionnaire ( 84 recommendations) is quite high.

Indicators based on guidelines mainly lead to process indicators and structure indicators. We used the guideline as a starting point for the development of clinical indicators for patients with functional constipation. By following this procedure, the final set of indicators includes only structure indicators (e.g. Availability of a brochure on pediatric constipation in the consulting-room) and process indicators (e.g. Percentage of patients with constipation that received lactulose as initial or maintenance treatment). This phenomenon has also been identified in similar selection procedures $[9,23,24]$. Optimal care according to the guidelines should lead to better outcomes of care, although outcome indicators themselves are not part of the guidelines. Therefore, outcome indicators do not originate from our development procedure and adding a set of outcome indicators, such as mortality, morbidity, quality of life and patient satisfaction, could be considered.

Although process indicators are better suited for quality improvement than outcome indicators, insurers, policy makers and consumers are usually more interested in outcome measures. However, outcome measures have major disadvantages: they usually have a low incidence or prevalence and therefore need long periods of observation; they are difficult to control because they are also influenced by lifestyle choices of patients, compliance and health status; and they are heavily confounded, for example by disease stage $[9,20,29]$. Process and structure indicators, on the other hand, are easy to measure, do mostly not require case mix adjustment and are therefore considered more valuable for quality improvement programs, when compared with outcome measures.

The development of clinical indicators should be followed by a practice test. During the practice test for the indicators for childhood functional constipation, it became clear that not all information needed to measure the indicators was easily accessible. Collecting the information needed was time-consuming for professionals, which is an often heard criticism. The time spent on data collection could better be spent on patient care. An electronic medical record with standardized templates could minimize this burden. At best, information on the indicators is routinely collected so that instant feedback is possible, which can lead to the continuous improvement activities.

Indicators give insight into determinants and variation in actual care. This is needed to target the improvement strategy $[2,6,26,31,32]$. Evidence suggests that educational outreach visits, education meetings, workshops and audit- and feedback-based quality indicators can be effective in changing health care practice $[10,17,25]$. Grol et al. showed that studies using feedback reports combined with other implementation strategies, such as the use of education and quality improvement plans, were most effective in improving quality of care [11, 13, 14]. Therefore, we suggest the development of an implementation strategy, including at least audit and feedback, in order to implement the guideline 'Functional constipation in children between 0 and 18 years' and its quality indicators.

In conclusion, based on evidence from the literature, expert opinions and a systematic methodology, we have developed a set of process and structure indicators to monitor the quality of health care for children with functional constipation. This set of quality indicators could be helpful during the implementation of the evidence-based multidisciplinary guideline 'Functional constipation in children between 0 and 18 years'. This development procedure could serve as an example for others in their efforts to implement guidelines into practice.

Acknowledgements We would like to thank all members of the expert panel for their contributions to the development of the quality indicators: M. Berger (University Medical Centre, Groningen), A. Bluyssen (Sophia Hospital, Rotterdam), N. Boluyt (Emma Children's Hospital/Academic Medical Centre, Amsterdam), A. Bulk (VU University Medical Centre, Amsterdam), E. Ekkerman (VU University Medical Centre, Amsterdam), M. Ernst-Kruis (Meander Medical Centre, Amersfoort), B. Gonera-de Jong (Wilhelmina Hospital Assen/University Medical Centre Groningen), M. Groeneweg (Maasstad Hospital, Rotterdam), A. van den Hurk (Erasmus Medical Centre, Rotterdam), C. Kuijper (Emma Children's Hospital/Academic Medical Centre, Amsterdam), M. Kurver (Dutch association of general practitioners, Utrecht), E. van Kuyk (University Medical Centre Nijmegen), T. Liem (University Medical Centre Utrecht), M. Meuldijk (Erasmus Medical Centre, Rotterdam), M. Offeringa (Patient Society of Anus atresia), C. Penning (Intellectual Disability Medicine, Erasmus Medical Centre/University Medical Centre, Rotterdam), R. van der Plas (Leids University Medical Centre, Leiden), C. Vermoen (Stichting Zuidwester, Middelharnis) and L. Wittmarschen (Patient Society of Hirschsprung's Disease, Hilversum).

Conflict of interest The authors declare that they have no conflict of interest.

Open Access This article is distributed under the terms of the Creative Commons Attribution Noncommercial License which permits any noncommercial use, distribution, and reproduction in any medium, provided the original author(s) and source are credited.

\section{References}

1. Benninga MA, Voskuijl WP, Taminiau JA (2004) Childhood constipation: is there new light in the tunnel? J Pediatr Gastroenterol Nutr 39:448-464 
2. Campbell SM, Braspenning J, Hutchinson A, Marshall MN (2003) Research methods used in developing and applying quality indicators in primary care. BMJ 326:816-819

3. Campbell SM, Cantrill JA, Roberts D (2000) Prescribing indicators for UK general practice: Delphi consultation study. BMJ 321:425-428

4. Cantrill JA, Sibbald B, Buetow S (1998) Indicators of the appropriateness of long-term prescribing in general practice in the United Kingdom: consensus development, face and content validity, feasibility, and reliability. Qual Health Care 7:130-135

5. CBO. Dutch guideline: functional constipation in children between 0 and 18 years. CBO: Utrecht, 2009

6. De Vos M, Graafmans W, Kooistra M, Meijboom B, Van der Voort P, Westert G (2009) Using quality indicators to improve hospital care: a review of the literature. Int $\mathrm{J}$ Qual Health Care 21:119-129

7. Di Lorenzo C (2000) Childhood constipation: finally some hard data about hard stools! J Pediatr 136:4-7

8. Donabedian A (1980) Explorations in quality assessment and monitoring: the definition of quality and approaches to its assessment. Health Administration Press, Michigan

9. Eddy DM (1998) Performance measurement: problems and solutions. Health Aff Millwood 17:7-25

10. Forsetlund L, Bjorndal A, Rashidian A, Jamtvedt G, O'Brien MA, Wolf F, Davis D, Odgaard-Jensen J, Oxman AD (2009) Continuing education meetings and workshops: effects on professional practice and health care outcomes. Cochrane Database Syst Rev 2:CD003030

11. Grol R (2001) Improving the quality of medical care: building bridges among professional pride, payer profit, and patient satisfaction. JAMA 286:2578-2585

12. Grol R, Baker R, Moss F (2002) Quality improvement research: understanding the science of change in health care. Qual Saf Health Care 11:110-111

13. Grol R, Grimshaw J (2003) From best evidence to best practice: effective implementation of change in patients' care. Lancet $362: 1225-1230$

14. Grol R, Wensing M, Eccles M (2005) Improving patient care; the implementation of change in clinical practice. Elsevier, Butterworth

15. Hermanides HS, Hulscher ME, Schouten JA, Prins JM, Geerlings SE (2008) Development of quality indicators for the antibiotic treatment of complicated urinary tract infections: a first step to measure and improve care. Clin Infect Dis 46:703-711

16. Hermens RP, Ouwens MM, Vonk-Okhuijsen SY, Van der Wel Y, Tjan-Heijnen VC, Van den Broek LD, Ho VK, Janssen-Heijnen ML, Groen HJ, Grol RP, Wollersheim HC (2006) Development of quality indicators for diagnosis and treatment of patients with non-small cell lung cancer: a first step toward implementing a multidisciplinary, evidence-based guideline. Lung Cancer 54:117-124

17. Jamtvedt G, Young JM, Kristoffersen DT, O'Brien MA, Oxman AD (2006) Audit and feedback: effects on professional practice and health care outcomes. Cochrane Database Syst Rev 2: CD000259

18. Kravitz RL, Park RE, Kahan JP (1997) Measuring the clinical consistency of panelists' appropriateness ratings: the case of coronary artery bypass surgery. Health Policy 42:135-143

19. Mainz J (2003) Defining and classifying clinical indicators for quality improvement. Int J Qual Health Care 15:523-530
20. Mant J (2001) Process versus outcome indicators in the assessment of quality of health care. Int J Qual Health Care 13:475-480

21. McGlynn EA, Asch SM (1998) Developing a clinical performance measure. Am J Prev Med 14:14-21

22. Molnar D, Taitz LS, Urwin OM, Wales JK (1983) Anorectal manometry results in defecation disorders. Arch Dis Child 58:257-261

23. Mourad SM, Hermens RP, Nelen WL, Braat DD, Grol RP, Kremer JA (2007) Guideline-based development of quality indicators for subfertility care. Hum Reprod 22:2665-2672

24. Nelen WL, Hermens RP, Mourad SM, Haagen EC, Grol RP, Kremer JA (2007) Monitoring reproductive health in Europe: what are the best indicators of reproductive health? A need for evidence-based quality indicators of reproductive health care. Hum Reprod 22:916-918

25. O'Brien MA, Rogers S, Jamtvedt G, Oxman AD, Odgaard-Jensen J, Kristoffersen DT, Forsetlund L, Bainbridge D, Freemantle N, Davis DA, Haynes RB, Harvey EL (2007) Educational outreach visits: effects on professional practice and health care outcomes. Cochrane Database Syst Rev 4:CD000409

26. Ouwens MM, Marres HA, Hermens RR, Hulscher MM, Van den Hoogen FJ, Grol RP, Wollersheim HC (2007) Quality of integrated care for patients with head and neck cancer: development and measurement of clinical indicators. Head Neck 29:378-386

27. Perry M, Draskovic I, Van Chterberg A, Van Eijken M, Lucassen P, Vernooij-Dassen M, Olde RM (2010) Development and validation of quality indicators for dementia diagnosis and management in a primary care setting. J Am Geriatr Soc 58:557-563

28. Pijpers MA, Tabbers MM, Benninga MA, Berger MY (2009) Currently recommended treatments of childhood constipation are not evidence based: a systematic literature review on the effect of laxative treatment and dietary measures. Arch Dis Child 94:117-131

29. Pronovost PJ, Miller MR, Dorman T, Berenholtz SM, Rubin H (2001) Developing and implementing measures of quality of care in the intensive care unit. Curr Opin Crit Care 7:297-303

30. Rubin HR, Pronovost P, Diette GB (2001) From a process of care to a measure: the development and testing of a quality indicator. Int J Qual Health Care 13:489-496

31. Rutten GM, Degen S, Hendriks EJ, Braspenning JC, Harting J, Oostendorp RA (2010) Adherence to clinical practice guidelines for low back pain in physical therapy: do patients benefit? Phys Ther 90:1111-1122

32. Schouten JA, Hulscher ME, Wollersheim H, Braspennning J, Kullberg BJ, Van der Meer JW, Grol RP (2005) Quality of antibiotic use for lower respiratory tract infections at hospitals: (how) can we measure it? Clin Infect Dis 41:450-460

33. Shekelle PG, Chassin MR, Park RE (1998) Assessing the predictive validity of the RAND/UCLA appropriateness method criteria for performing carotid endarterectomy. Int $\mathrm{J}$ Technol Assess Health Care 14:707-727

34. Shekelle PG, Kahan JP, Bernstein SJ, Leape LL, Kamberg CJ, Park RE (1998) The reproducibility of a method to identify the overuse and underuse of medical procedures. N Engl J Med 338:1888-1895

35. Taitz LS, Wales JK, Urwin OM, Molnar D (1986) Factors associated with outcome in management of defecation disorders. Arch Dis Child 61:472-477

36. Van den Berg MM, Benninga MA, Di LC (2006) Epidemiology of childhood constipation: a systematic review. Am J Gastroenterol 101:2401-2409 